\title{
Analysis of the Negative Emotion Sources of Employees and Management Countermeasures
}

\author{
Xiangwang Zheng and Lijin Shao \\ Fuzhou Meilbourne Polytechnic
}

\begin{abstract}
In the process of enterprise management, some employees will show a negative attitude in work, and such attitude will generally cause tension, suppression, boredom and other negative emotions, and will largely reduce work efficiency. This paper attempts to analyze the influencing factors and sources of employees' negative emotion, and then through management concept, management mechanism, evaluation mechanism, enterprise culture and other aspects, it finds reasonable management methods to alleviate the negative emotions of employees, and then decrease the influence of negative emotions on work to the largest extend.
\end{abstract}

Keywords-Negative emotions; Emotion management; Management countermeasures

\section{INTRODUCTION}

In the enterprise management process, partial employees show a kind of negative attitude in work, and such emotion will generally cause tension, suppression, boredom and other negative emotions, and then decrease the work efficiency of employees, being accompanied with knowing nothing to do, tension and anxiety as well as indifferent expressions. In the employee management process, if enterprises fail to pay attention to it, the negative emotions of employees will be increasingly stronger, and this will finally cause the failure in working at post, which can have a big influence eon enterprise development. Thus, enterprises should timely analyze the negative emotion source of employees, and formulate corresponding management methods for the negative emotion of employees [1]. In the management process, it is requested to observe and analyze from different types of negative emotion sources, and pointedly formulate corresponding management countermeasures.

\section{INFLUENCE BROUGHT BY NEGATIVE EMOTIONS OF EMLOYEES ON WORK}

Under the influence of the outside world and its own factors, employees will generate certain emotion changes. Such emotion changes are called by the academic world as tipping point. The influence degree of the tipping point on different employees will also be different.

The work influence expressed by negative emotions is mainly expressed as follows:

(1) Generate boredom in work; after employees have negative emotions, they will feel bored about some relatively difficult work or work with relatively strong repeatability, and due to the influence of negative emotions, it is easily to generate boredom in work. Under the influence of boredom, employees will generate bluntness, low concentration in thinking consciousness, decreased reaction speed and other problems. Due to the influence of negative emotions, the work efficiency of employees will be decreased to a great extent, and then influence the development of the entire enterprise [2].

(2) Generate anxiety emotions in work; in the working process, when carrying out new project, various factors will result in the failure for many people to carry out work successfully. Under such working status, due to the relatively weak psychological endurance, it will easily incur tense interpersonal relationship, and then show a kind of anxious emotions in work. Such emotion can cause the increase in the epinephrine of employees, generate fear psychologically, always work in fear and trembling throughout the day, and can easily get excited, and will have a kind of unsatisfied expressions for work and colleagues.

(3) Generate the sense of loss in work; the generation of the sense of loss is incurred by the work pressure to a large extent, and when the working pressure of employees is relatively big, and heavy work has made them have little personal time. This has cause the unbalance of their work and life to some extent, and they can always feel like missing something inside. Besides, with the influence of negative emotions, they can easily get tired in work, and will also have void problems in the expression of psychological features [13].

\section{ANALYSIS OF THE GENERATION SOURCE OF EMPLOYEES' NEGATIVE EMOTIONS}

The source generating the employees' negative emotions can be influenced by various factors, such as individual, family, work, and feelings, and they are all sources of employees' negative emotions. In the process for modernized enterprises to conduct employee management, it is requested to carefully analyze the source of employees' negative emotions, and lay a solid foundation for realizing the management of employees' negative emotions; meanwhile, it is also a valid approach for improving the operation efficiency of enterprise operation. Through analyzing from the current source of employees' negative emotions, the main reason is the influence brought by enterprise culture on employees, and the influence of enterprise culture on employees can be reflected in many aspects. Thus, enterprise culture is a kind of work guidance specific to the entire enterprise employees, and only excellent enterprise culture can create a good working atmosphere for employees, 
and make employees keep smooth emotions in work, and alleviate the negative emotions brought thereby to a large extent. If enterprise culture is inadequate, the working environment of employees cannot be assured, and employees can easily generate all kinds of different negative emotions. If the situation is serious, employees' negative emotions will also be extended in work, and generate influence on the entire department and even the entire enterprise [3]. Thus, through analyzing from the reasons generating employees' negative emotions, the biggest factor generating negative emotions is work reasons. From such perspective, in order to alleviate employees' negative emotions, it is requested to analyze from enterprise culture, build excellent enterprises for employees, and make them work in a good working environment.

Besides, except the influence of enterprise culture on employees' negative emotions, there are also many other factors influencing the generation of employees' negative emotions, such as gender, age, marriage status, education degree, and working post. These factors will also generate a subtle influence on the employees' negative emotions. The influence of gender factor on employees' negative emotions is mainly expressed in capacity and qualification. In enterprises, the capacity and qualification of males are stronger than those of females, and the negative emotions incurred by these factors are commonly seen in female employees. The influence of age factor on the employees' negative emotions is mostly expressed in the organization factor. Young employees can lack in self-actualization, capacity accomplishment, work relationship, performance, and organization factor [4]. For some young and middle-aged employees, these factors have become increasingly mature, so for young and elder employees, they can generate certain negative emotions. The influence of marriage status on employees' negative emotions is also not obvious, unmarried employees have certain advantages in capacity and quality, self-actualization, work relation and other aspects, so in the process for carrying out actual work, there are no excessive influence of negative emotions. Married employees prefer to bring better life conditions for their families through hard work, so they will express active and positive emotions in all aspects. The influence of education degree on employees' negative emotions is mainly expressed in capacity and quality, self-actualization and work relation, because employees with higher education degree have stronger capacity when carrying out work. However, employees with lower education degree have low comprehensive quality in work, and have disadvantages to some extent, so they will generate negative emotions about the work engaged thereby. The influence of working post on employees' negative emotions is mainly expressed in capacity and quality and selfactualization, because some employees will think that posts decide their own future during the process to carry out work, and once they cannot work at the expected post, they will generate certain negative emotions [5].

\section{EMPLOYEES' NEGATIVE EMOTION MANAGEMENT COUNTERMEASURES}

\section{A. Adhere to people-oriented management concept}

In the process for enterprises to carry out the management of employees' negative emotions, it is requested to adhere to people-oriented management concept. Integrate peopleoriented management concept into enterprise culture, and make it become an important thought to guide employee' thoughts, and this is also a necessary development of modernized enterprise management. Currently, many enterprises still adopt intensive management when carrying out employee management and its management mode has formed big restriction on the personality development of employees, and then make employees express a kind of unsatisfied psychology in the working process and make them generate negative emotions for enterprise management. Thus, in the enterprise management system, in order to improve the management efficiency, it is requested to adopt humanized management and guide the negative emotions of employees, and do not implement oppressive management on the negative emotions of employees. Such management mode will only increase the negative emotions of employees, and seriously influence enterprise development. Enterprises should give maximum respect to employees, and only when employees receive respect individually, they can reflect people-oriented management concept in a real sense [6].

\section{B. Perfect relevant management mechanism and evaluation system}

When receiving enterprise management, employees have certain autonomous right. If enterprises conduct forcing management, they can only make the resistance psychology of employees increasingly strong, and then increase the negative emotions of employees. Enterprises should timely perfect relevant management mechanism, and it is applicable to alleviate the negative emotions of employees through the mode of appropriately improving relevant welfare treatment level [7]. Meanwhile, it is also requested to build a good working atmosphere, and make it complete each work in a good working atmosphere with happy emotions, and then make employees overcome their negative emotions, improve work efficiency while increasing their sense of identity and belonging for the enterprise.

\section{Build excellent enterprise culture}

(1)Build a good working atmosphere; in the process of carrying out the management of employees' negative emotions, enterprise culture plays an extremely important role. Enterprises should build excellent enterprise culture for employees, and make them carry out actual work in a good working atmosphere. In such working atmosphere, employees can better alleviate, which can be good for eliminating and controlling employees' negative emotions. Through analyzing in some sense, there are many sources of employees' negative emotions; meanwhile, there are also many uncertain factors. In order to alleviate the influence of employees' negative emotions on work, and prevent the intensification of employees' negative emotions in work, enterprises are 
requested to build a good enterprise culture. It is requested to regard the working environment of employees as the cutting point, and make it become a critical link for guiding employees to alleviate negative emotions. In a good working atmosphere, employees' negative emotions can be slowly alleviated, and they will use the mode of commitment to slowly eliminate and control their own negative emotions. As for the enterprise management personnel, they should realize the importance of enterprise culture construction, and list enterprise culture into the development plan of the enterprise, and make it become the core construction objective. Through good enterprise culture, decrease the influence of employees' negative emotions on work, improve the work efficiency of employees, and promote the long-term and stable development of the enterprise [7].

(2)Regard the positive energy of enterprise culture as the guidance; in the process of building enterprise culture, management personnel are requested to seize the key requirements of the enterprise, and make them right-hand men guiding the working thoughts of employees. For instance, more positive enterprise cultural concepts with stronger positive energy are integrated in enterprise culture, to decrease the probability for the generation of employees' negative emotions to a certain extent. Make employees feel the sense of belonging in work, and the strong sense of identity for enterprise development and their own work. Under the effect of enterprise culture, employees should correctly cognize their own capacities, and regard the surrounding colleagues as the model, hold aggressive and positive attitude, and work hard. Specific to self-deficiency, make compensation, reasonably control their emotions and decrease the generation of negative emotions. Thus, the construction of enterprise culture requires reasonable and scientific method. Enterprise management personnel should also timely realize the importance of this point, and it is applicable to refer to successful cases of other enterprises, formulate a kind of valid strategies suitable for the enterprise development and individual profits of employees. Highlight the position and role of employees in work, ensure the loyalty of employees for enterprises, and then through reasonable profit distribution mechanism, increase the sense of responsibility for employees, and promote employees' emotion adjustment and control [8].

(3)Regard humanized service as the guidance, and while managing the negative emotions of employees, it is not requested to forcibly compress employees' negative emotions. Such wrong approach can only increase the negative emotions of employees. It is requested to combine different negative emotions generated by employees, provide humanized guidance, and select suitable opportunities to get involved in the management of employees' negative emotions through the mode of humanized management, and meanwhile, formulate corresponding coping measures, and provide humanized and diversified service types for employees [9]. For instance, when employees have big working pressure in work, this will increase the probability for employees to generate negative emotions to some extent. Thus, enterprises should irregularly hold some activities for employees that can release pressure. Encourage all employees to participate in these activities, and let employees aware the influence of negative emotions on work, and themselves. It is also applicable to periodically organize employees to participate in some entertainment activities of the enterprise, such as tourism and picnic. Let employees alleviate the working pressure in entertainment, and then decrease the rate of occurrence for employees' negative emotions. Conditional enterprises can also organize some activities, lectures and training for employees to alleviate the pressure. Make employees practically feel about the humanized management of the enterprise, which can be good for employees to remove and control negative emotions. When managing the negative emotions of employees, enterprises can provide various humanized service types, and can also provide some humanized vacation services and welfare services for employees. When selecting corresponding service, enterprise should select as per its own actual emotions and the characteristics about the negative emotions of employees, so as to alleviate the negative emotions of employees to a large extent [10].

(4)The humanized service process should be specific and targeted. In such link, enterprises should realize the main objective for the management of employees' negative emotions is to control the negative emotions of employees, rather than forcibly suppressing the negative emotions of employees, and this is related to the key for the advantages and disadvantages in implementing the management of employees' negative emotions. Enterprises can set professional management department, and formulate suitable humanized service specific to the work features and properties of its own enterprise, and realize specific and targeted humanized service [11]. For instance, when enterprises increase the working strength of employees in development, most employees will generate certain working pressure. Such negative emotions will become common negative emotions among enterprise employees. Or due to unsuccessful enterprise development, employees will show confusion in work, and even loose development impetus, such negative emotions will fast spread in the entire enterprise. Enterprises should timely take the development conditions as the cutting point, formulate corresponding management methods for employees' negative emotions [12]. Use multiangle, diversified, and practical methods to manage the negative emotions of employees. Specific to the employees' negative emotions generated under different periods and different backgrounds, it is requested to select suitable service project and activities.

\section{CONCLUSION}

To sum up, in the process for enterprises to carry out negative emotion management of employees, it is requested to analyze in combination with the actual conditions of enterprises and study the source generating the negative emotions of employees, so as to formulate effective solutions. As for the negative emotions of employees, it is not requested to completely prohibit the existence of negative emotions through management, instead, it is requested to control it with reasonable and humanized methods through managing the negative emotions of employees. Let employees carry out work in a good enterprise culture atmosphere, and through the humanized management carried out by enterprises, reinforce the sense of identity and belonging for the enterprise. Through such method, it can alleviate the negative emotions of 
employees to the largest extent, and through specific and objective management methods, eliminate and control the negative emotions of employees, and minimize the influence of employees' negative emotions on work. Through the reasonable, scientific and humanized negative emotion management of employees carried out by enterprises, it can improve the work efficiency of employees, and lay a foundation for the long-term and stable development of enterprises.

\section{REFERENCES}

[1] Lu Zhao. Analysis on the Emotion Management of Employees [J]. Chinese Talent, 2011, (01): 55-56.

[2] Lu Yang. Profession, Attitude and Emotion Management [J]. Journal of CNPC Managers Training Institute, 2012, (04): 54-56.

[3] Hui Liu. Labor Emotion Management Series VI The Key to Open Emotion Management [J]. China Petrochem, 2010, (22): 82-83.

[4] Hui Liu and Xinlong Mi. Labor Emotion Management Series V Emotion Management, Managing Emotions Well [J]. China Petrochem, 2010, (21): 82-83.

[5] Hui Liu. How to Let Enterprises Conduct Systematic Emotion Management [J]. China Machinery \& Electric Industry, 2010, (12): 5657.

[6] Jinming Chen and Zhonghua Wu. How to Manage the Emotion of Employees [J]. Construction Enterprise Management, 2009, (07): 76-77.

[7] Lin Bao, Guiwei Zhang and Debin Zhang. Enterprise Employee Emotion Management under the Perspective of Organization [J]. Enterprise Economy, 2014, (03): 47-50.

[8] Furong Xiang. Discussion about the Application of Emotion Management in Office Work [J]. Modern Economic Information, 2014, (02): 112-112.

[9] Lidan Li. Discussion about the Application of Emotion Management in Enterprise Human Resource Management [J]. Enterpriser World (Second Semimonthly), 2014, (05): 3-5.

[10] Xinyu Zhou and Jianzhong Wang. Exploration about the Emotion Management Mechanism of Employees in SMEs [J]. Liaoning Economic Management Cadre College (Journal of Liaoning College of Economics and Technology), 2014, (05): 22-24.

[11] Guoxi Chen and Yinji Cui. Research about the Emotion Management of Enterprise Employees [J]. Operation Manager, 2013, (30): 1-2.

[12] Jing Fan. Analysis on the Influence of Emotion Management on the Work Performance of Enterprise Employees [J]. Human Resource Management, 2013, (10): 10-12.

[13] Huantian Xu. Methods and Approaches for Enterprises to Conduct Well Emotion Management [J]. Petroleum Political Work Research, 2011, (03): 52-54. 